\title{
Primary Peritoneal Serous Carcinoma: A Case Report
}

Nanda Patil $^{1 *}$, Manisha Laddad ${ }^{2}$, Shoaib Khoja ${ }^{3}$, Garima Agarwal ${ }^{3}$, Divya Brahmbhatt ${ }^{3}$, Vaidehi Nagar ${ }^{3}$

${ }^{1}$ Professor, Department of Pathology, ${ }^{2}$ Associate Professor, Department of Obstetrics and Gynaecology, ${ }^{3}$ Tutor, Department of Pathology, Krishna Institute of Medical Sciences, Deemed to be University, Karad, India

DOI: $\underline{10.36347 / \text { sjams.2020.v08i06.010 }}$

| Received: 31.05 .2020 | Accepted: 09.06.2020 | Published: 13.06.2020

*Corresponding author: Nanda Patil

\section{Abstract}

Primary peritoneal serous carcinoma (PPSC) is a rare malignancy which is seen in postmenopausal women. The diagnosis requires exclusion of serous carcinoma arising from ovaries and fallopian tubes. Histological diagnosis of PPSC is necessary to rule out other pathological conditions like malignant mesothelioma, pseudomyxoma peritonei and peritoneal carcinomatosis. We present a case of PPSC in a 52 years old female patient having complaints of abdominal mass and pain in abdomen. The patient was clinically diagnosed as primary ovarian carcinoma with peritoneal metastasis.

Keywords: Serous carcinoma, Peritoneum, Primary, Immunohistochemistry.

Copyright @ 2020: This is an open-access article distributed under the terms of the Creative Commons Attribution license which permits unrestricted use, distribution, and reproduction in any medium for non-commercial use (NonCommercial, or CC-BY-NC) provided the original author and source are credited.

\section{INTRODUCTION}

Primary peritoneal serous carcinoma is a rare entity which seen in elderly women. It is defined as primary tumour of peritoneum which involves surface of peritoneum in a diffuse fashion and spares or superficially invades ovaries and fallopian tubes [1]. It arises from the coelomic epithelial lining of the pelvic peritoneum. The clinical presentation of this tumour is like ovarian carcinoma with peritoneal metastasis.

\section{Case Report}

A 52 years old postmenopausal female patient presented with complaint of pain in lower abdomen and abdominal distention since 2 months. CT abdomen and pelvis revealed peritoneal lesion measuring 12.6 x 10.9 $\mathrm{x} 7.8 \mathrm{~cm}$ which was solid and cystic suggesting possibility of peritoneal metastasis. Exploratory laparotomy was done and patient underwent hysterectomy with bilateral salpingoophorectomy and removal of peritoneal mass along with pelvic omentum. The specimen was sent for histopathological examination.

\section{Histopathological Examination-}

Gross examination revealed a mass of size $6 \mathrm{x}$ $4.5 \times 4 \mathrm{~cm}$. External surface of mass was smooth and intact \& cut section showed solid and cystic, grey brown tumour with area of necrosis and haemorrhage(Fig-1 and 2).

Specimen of hysterectomy and bilateral salpingoophorectomy did not reveal tumor tissue(Fig-3 and 4). Also seperately sent pelvic omentum did not reveal tumor tissue.

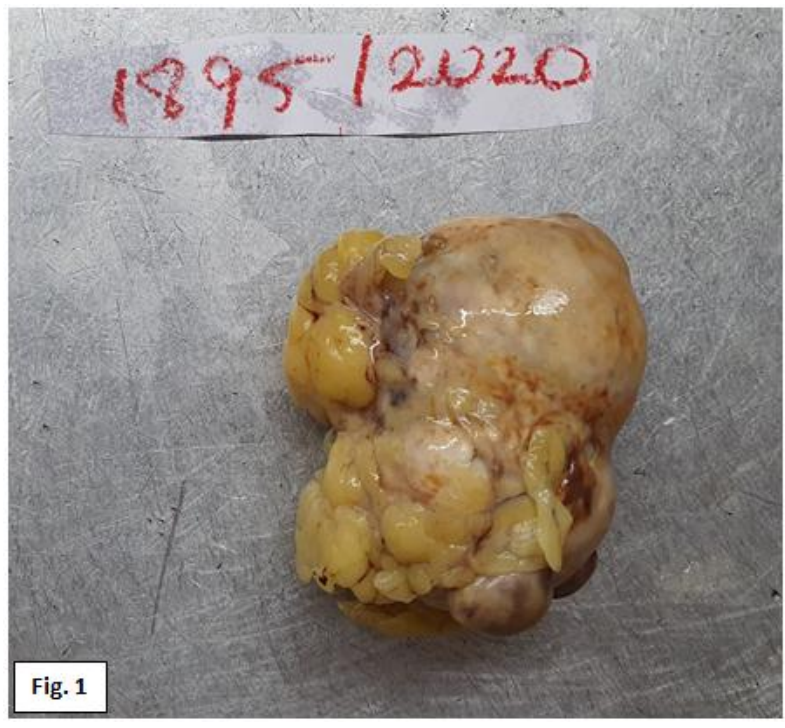

Fig-1: A tumor mass of size $6 \times 4.5 \times 4 \mathrm{~cm}$ with intact external surface 


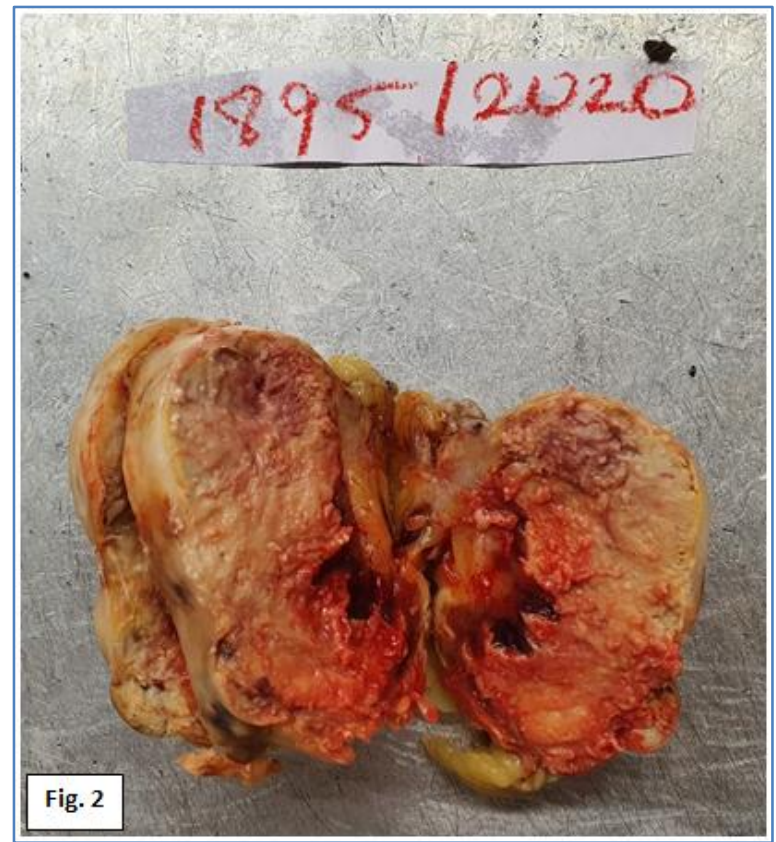

Fig-2: Cut section of tumor showing solid and cystic areas with extensive necrosis

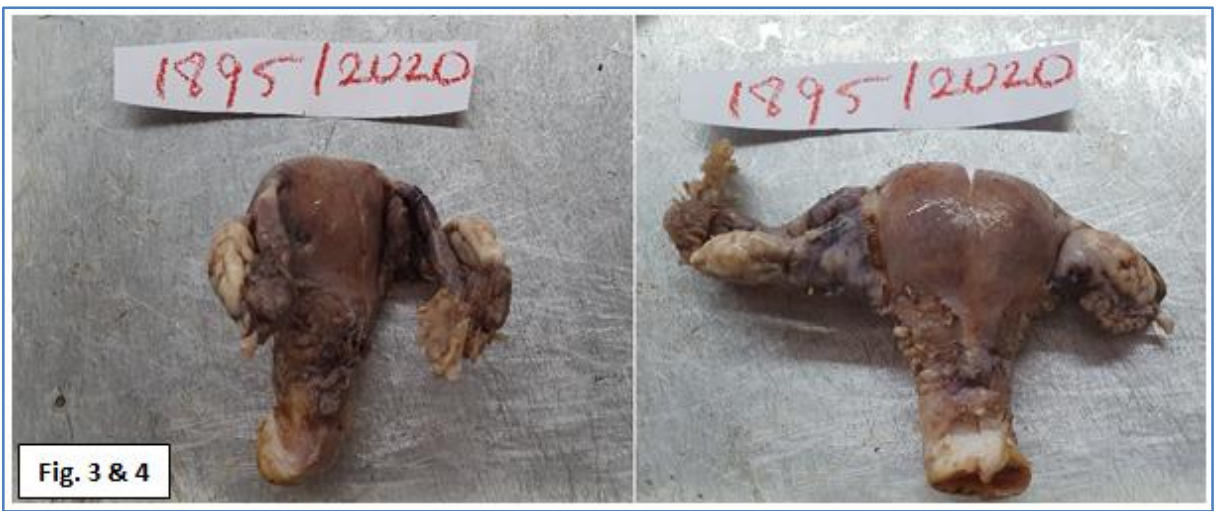

Fig-3 \& 4: External surface and cut section of uterus, cervix and bilateral adnexa reveal no evidence of tumor

Microscopic examination from tumour tissue revealed extensive coagulative necrosis and a small part of viable tumour arranged in papillary structures, nest and sheets. Tumour cells showed highly pleomorphic nuclei with high mitotic index. Psammoma bodies were noted in the viable portion of tumour (Fig-5,6).

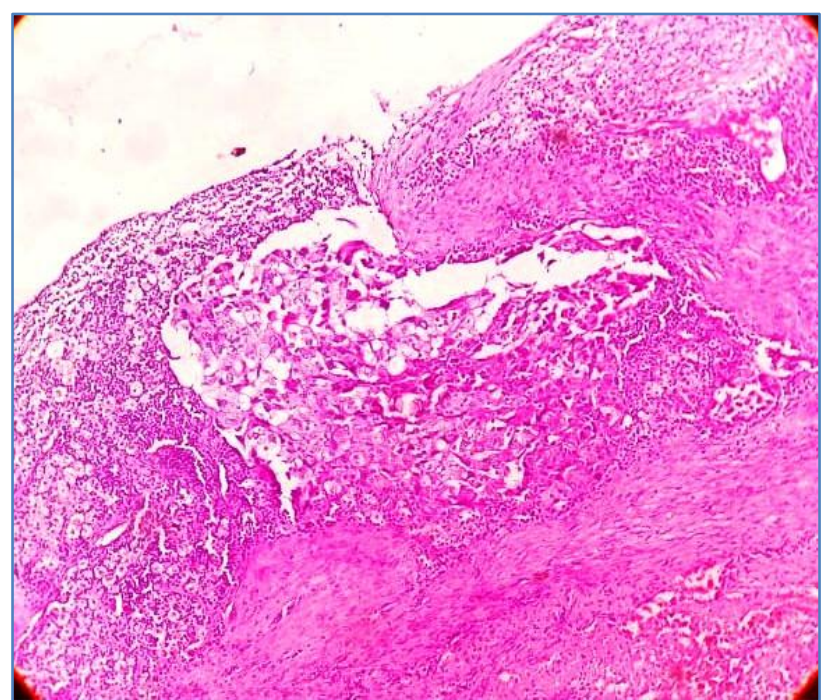

Fig-5: A small viable tumor seen in solid pattern and nests with extensive tumor necrosis $(\mathrm{H} \& \mathrm{E}-100 x)$ 


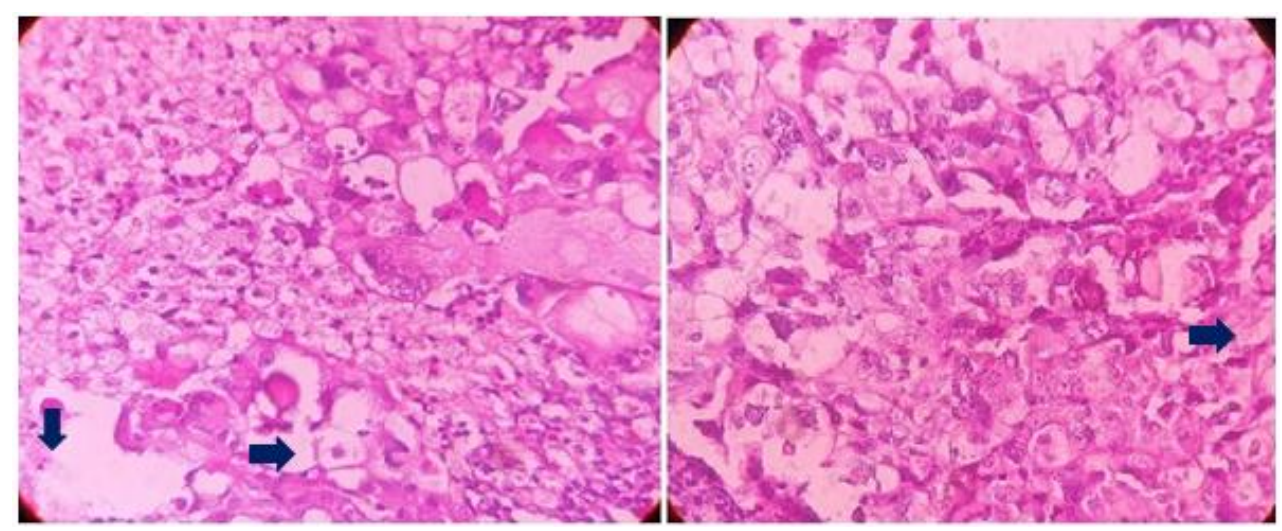

Fig-6: Tumor cells showing bizzare pleomorphic nuclei. Arrow shows psammoma bodies (H\&E 400 xs)

Microscopic examination of uterus, cervix, bilateral ovaries and fallopian tubes and omentum did not reveal tumour tissue. The representative blocks of tumour tissue were sent for immunohistochemistry. The tumour revealed positivity for CK7, PAX8, WT1, ER and P53. Tumour showed negativity for IHC markers CK20 and CDX2 which rules out the possibility of metastasis of colorectal carcinoma. Considering the microscopic features and positive IHC markers for CK7, PAX8, WT1, ER and P53 and no evidence of tumour in ovaries and fallopian tubes, the diagnosis was given as high grade Primary Peritoneal Serous Carcinoma.

\section{DISCUSSION}

Primary peritoneal serous carcinoma is extremely rare malignancy. It was first described in 1972 by Lauchlan, he shared coelomic epithelial lining of the pelvic peritoneum as the embryonic origin of this tumour [2]. Most cases of PPSC are observed in elderly postmenopausal women [3]. Our case also revealed similar findings. The incidence of PPSC in the United States is 6.78/1000000 individuals [4].These tumours can be solitary or multifocal [5]. Most PPSC present as high grade, rapidly invasive tumour with extensive spread. Our patient also presented with high grade tumour with extensive coagulative necrosis.

A diagnosis of PPSC is based on the Gynaecology Oncology Group Criteria as follows:

1) The ovaries should be normal in size.

2) The involvement of extra ovarian site is greater than involvement of surface of ovary.

3) Absence of deep seated invasive ovarian carcinoma.

4) Histopathological characteristic of tumour similar to epithelial ovarian cancer (6).

Pre-operative correct diagnosis of PPSC is difficult as most of the times the tumour is multifocal and misdiagnosed as peritoneal carcinomatosis from ovarian or gastrointestinal cancer. Our case was also preoperatively diagnosed as peritoneal carcinomatosis from ovarian carcinoma.
On immunohistochemical Examination, PPSC are typically positive for Cytokeratin7 (CK7), CA125, Estrogen Receptor, WT1 and PAX8.Our case also revealed positivity for $\mathrm{CK} 7, \mathrm{WT} 1, \mathrm{ER}$ and PAX8. These markers are also helpful in identifying Mullerian derived tumour and thus excluding metastasic malignancy and malignant mesothelioma [7-9]

Studies have revealed significantly worse prognosis in PPSC, Five years survival rate being 0$26.5 \%$ and median survival between 7 to 27.7 months. The treatment includes hysterectomy with bilateral salpingoophrectomy and debulking surgery followed by platinum-based chemotherapy [10].

\section{Conclusion}

Primary peritoneal serous carcinoma is a rare and distinct tumour seen in postmenopausal women. Definitive pre-operative diagnosis of PPSC is not possible, histopathological examination of the tumor with IHC studies play a key role in making final diagnosis.

\section{REFERENCES}

1. Morita H, Aokil J, Taketomi A, Sato N, Endo K. Serous surface papillary carcinoma of theperitoneum: clinical, radiologic and pathologic findings in 11 patients. Am J Roentgenol. 2004;183:923-8.

2. Lauchlan SC. The secondary müllerian system. Obstet Gynecol Surv. 1972; 27:133-46.

3. Goswami SS, Oza RM, Desai RI, Jasani J. Extra ovarian primary peritoneal carcinoma. Pathol Lab Med. 2010; 2:88.

4. Goodman MT, Shvetsov YB. Incidence of ovarian, peritoneal and fallopian tube carcinomas in the United States, 1995-2004. Cancer Epidemiol Biomarkers Prev. 2009; 18:132-139.

5. Muto MG, Welch WR, Mok SC, Bandera CA, Fishbaugh PM, Tsao SW. Evidence for a multifocal origin of papillary serous carcinoma of the peritoneum. Cancer Res. 1995;55:490-2.

6. Bloss JD, Liao SY, Buller RE, Manetta A, Berman ML, McMeekin S, Bloss LP, DiSaia PJ. 
Extraovarian peritoneal serous papillary carcinoma: A case-control retrospective comparison to papillary adenocarcinoma of the ovary. Gynecol Oncol. 1993;50:347-351.

7. Turnage RH, Badgwell B. Abdominal wall, umbilicus, peritoenum, mesentery, omentum and retroperitoneum. In: Townsend CM Jr, Beauchamp RD, Evers BM, Mattox KL, editors. Sabiston Textbook of Surgery. 19th. Saunders Elsevier; Philadelphia, PA: 2012; 1102.

8. Wang Y, Wang Y, Li J. PAX8: a sensitive and specific marker to identify cancer cells of ovarian origin for patients prior to neoadjuvant chemotherapy. J Hematol Oncol. 2013; 6:60.

9. Bayrak R, Haltas H, Yenidunya S. The value of CDX2 and cytokeratins 7 and 20 expression in differentiating colorectal adenocarcinomas from extraintestinal gastrointestinal adenocarcinomas: cytokeratin 7-/20+ phenotype is more specific than CDX2 antibody. Diagnostic pathology. 2012 Dec $1 ; 7(1): 9$.

10. Punyashetty KB, Shankar AA, Katti TV. Extraovarian primary peritoneal carcinoma: A clinicopathological gray zone. J Interdiscip Histopathol. 2014;2:104-7. 